\title{
A CONTRIBUIÇÃO DA AVALIAÇÃO IN LOCO COMO FATOR DE CONSOLIDAÇÃO DOS PRINCIPIOS ESTRUTURANTES DO SINAES
}

\author{
Thiago Henrique Almino Francisco* \\ Pedro Antonio de Melo** \\ Rogério da Silva Nunes*** \\ EXPEDITO MiCheLS**** \\ Maria Ines NaVa AzeVedo $* * * * *$
}

Recebido: 02 abr. 2011

Aprovado: 28 maio 2012

\begin{abstract}
* Mestre pelo Programa de Pós-graduação Stricto-Sensu Mestrado Profissional em Administração Universitária da Universidade Federal de Santa Catarina. Coordenador de Avaliação e Pesquisas Institucionais e Presidente da Comissão Própria de Avaliação da Faculdades Capivari. Capivari de Baixo, SC, Brasil. E -mail: proftf@gmail.com

** Doutor em Engenharia de Produção e Sistemas, pela Universidade Federal de Santa Catarina. Coordenador do Mestrado Profissional em Administração Universitária da Universidade Federal de Santa Catarina e Diretor do Instituto de Pesquisas e Estudos em Administração Universitária - INPEAU. Florianópolis, SC, Brasil. E-mail: pedro.inpeau@ufsc.com.br

*** Doutor em Administração pela Universidade de São Paulo. Professor adjunto da Universidade Federal de Santa Catarina. Florianópolis, SC, Brasil. E-mail: rogerionunes@cse.ufsc.br

**** Mestre pelo Programa de Pós-graduação Stricto-Sensu Mestrado Profissional em Administração Universitária da Universidade Federal de Santa Catarina. Diretor Geral da Faculdade Capivari e Presidente da Sociedade Educacional de Capivari de Baixo. Capivari de Baixo, SC, Brasil. E-mail: expedito@fucap.edu.br

$* * * * *$ Mestre pelo Programa de Pós-graduação Stricto-Sensu Mestrado Profissional em Administração Universitária da Universidade Federal de Santa Catarina. Chefe de Expediente no Departamento de Ciência e Tecnologia de Alimentos da UFSC. Florianópolis, SC, Brasil. E-mail: ines@cca.ufsc.br
\end{abstract}

Resumo: $\mathrm{O}$ artigo versa sobre a contribuição de avaliação in loco no sentido de promover a consolidação dos princípios norteadores do SINAES a partir de uma reflexão construtiva entre os consultores ad hoc e a instituição. A digressão teórica elenca aspectos relacionados a construção da identidade institucional, a partir da contribuição da avaliação e o retrospecto da avaliação institucional no Brasil. Elenca, ainda uma reflexão sobre o modelo do SINAES e os princípios estruturantes e norteadores do Sistema, destacando a contribuição do processo de avaliação in loco na construção da epistemologia institucional. Para tanto, as interações metodológicas ocorrem sob as bases da pesquisa acadêmica, de caráter documental indireto e que se classifica como sendo descritivaexplicativa, predominantemente qualitativa e designada como sendo uma pesquisa participante. As investigações construtivistas permitem concluir, entre outros desígnios, que do ponto de vista dos avaliadores ad hoc os aspectos que determinam o cumprimento dos princípios estruturantes do SINAES no contexto da avaliação institucional das instituições de educação superior no Brasil ensejam uma relação construtivista, democrática e de aprendizado mutuo e continuo entre avaliadores e a própria instituição, a qual é a responsável pela consolidação destes princípios no âmbito do ensino superior brasileiro.

Palavras-chave: Avaliação in loco. Princípios norteadores. SINAES. 


\author{
THE CONTRIBUTION OF ON-SITE EVALUATION AS A FACTOR \\ OF CONSOLIDATION OF THE STRUCTURING PRINCIPLES OF SINAES
}

\begin{abstract}
The paper focuses on the contribution of on-site evaluation in order to promote the consolidation of the guiding principles of SINAES based on the constructive thinking of consultants and the ad hoc institution. The theoretical discussion presents aspects related to the construction of institutional identity, based on the contribution of evaluation and on the definitions of institutional evaluation in Brazil. It also discusses Sinaes as a model along with the guiding principles that structure the System, emphasizing the contribution of the on-site evaluation process on the construction of institutional epistemology. Methodological interactions occur on the bases of academic research, of indirect documental character, which can be classified as descriptive-explanatory, predominantly qualitative and designed as participative research. The constructivist investigations allow us to conclude, among other things, that, from the standpoint of the peer review panel, the aspects that determine the compliance with the structural principles of Sinaes in the context of the institutional evaluation of higher education institutions in Brazil promote a constructivist and democratic relationship of mutual and continuous learning between evaluators and the institution itself, which is responsible for consolidating these principles in Brazilian higher education.
\end{abstract}

Key words: On-site evaluation. Guiding principles. SINAES.

\title{
1 ABORDAGENS PROPEDÊUTICAS
}

A proposta determinada à avaliação das instituições de ensino superior brasileiras considera, entre os diversos modelos institucionais, as premissas e demais objetivos diretamente vinculados à sua operacionalização. Por isso, SINAES (2009) corrobora o ensejo de Brasil (2004) e destaca a necessidade da participação efusiva da comunidade acadêmica no sentido de construir um conhecimento inerente ao desenvolvimento institucional.

O processo concebido no âmbito da avaliação, além de uma estruturação semântica, busca uma articulação epistemológica entre os diversos projetos institucionais e dos procedimentos metodológicos propostos pelos aspectos intrínsecos à avaliação. As proeminências avaliativas, sob a égide do aspecto técnico-conceitual, devem promover uma contribuição efetiva no sentido de consubstanciar o modelo avaliativo previsto no Plano Nacional da Educação para o decano $2001-2011$.

O documento inicial desta proposta, promulgada no ano de 2001, promove uma reflexão sobre a importância do modelo avaliativo proposto ao ensino superior brasileiro, o que é confirmado por Nogueira (2008), em vista da significativa expansão do segmento, confirmando-se a relevância das instituições privadas neste processo. Sob este aspecto, o SINAES enseja uma sistemática vinculada ao estudo estrutural de cursos e instituições, a partir de seus diversos modelos.

A partir desta estruturação, a avaliação concebida aos moldes do SINAES busca consolidar os procedimentos de reflexão e valoração institucional a 
partir de um retrato promovido pela contribuição de diversos instrumentos. $\mathrm{E}$ assim, com base no Decreto 6425 de 04 de abril de 2008, propondo o Censo de Educação Superior como sendo um instrumento adjacente e auxiliar aos procedimentos avaliativos.

$\mathrm{O}$ fomento do ensino superior sob um aspecto de qualidade perpassa a percepção de aspectos arrolados ao sistema formal proposto pelos órgãos reguladores. A proposta, no lume de uma orientação construtivista, deve buscar consolidar pressupostos e premissas que lhe servem de fundamento teóricometodológico ao arcabouço processual do sistema.

Na estruturação do sistema, SINAES (2009) destaca as considerações evidentes e determinantes que consolidam o ensino superior como um direito social e dever do estado. Neste caso, confirma-se o exposto no texto constitucional, especificamente no artigo 207, o qual transfere às instituições sob a orientação do Estado, o dever da oferta do ensino superior voltado às especificidades regionais e sociais. Contudo, ao assumir tal responsabilidade, as instituições devem esmerar-se em prestar contas à sociedade, cumprindo suas especificidades sob a flama da ética, produção de conhecimento e avanço científico.

A avaliação, tal como elenca Bittencourt, Casartelli e Rodrigues (2009), deve buscar a utilização de indicadores comuns aos diversos modelos institucionais, os quais buscam estruturar sistemáticas que consolidem os ensejos da sociedade. As instituições, neste contexto, devem ofertar respostas e prestar contas de suas atividades no âmbito de sua atuação, justificando as prerrogativas que lhe foram outorgadas.

Como evidenciado por SINAES (2009), a avaliação indica o compromisso inerente das instituições com seus valores sociais historicamente determinados, os quais visam direcionar o cumprimento das responsabilidades sociais a partir de uma perspectiva reflexiva. Este processo visa, entre outros termos, promover métodos de ensejo da liberdade de reflexão, criação, pensamento crítico, aprendizado e produção de conhecimento, especificamente educativos, os quais permitem refletir sobre o paradoxo da autonomia no cume das instituições de ensino superior no Brasil.

Na perspectiva destes termos, a avaliação institucional sob o contexto do SINAES estrutura-se no sentido de orientar uma eloquência formativa e determinante na produção de conhecimento direcionado à compreensão da sociedade. A partir dos pressupostos da era do conhecimento, a avaliação institucional contribui para evidenciar critérios de qualidade consistentes e aplicados às necessidades de uma sociedade que busca compreender suas preferências e seus modelos éticos, dominantes e históricos. 


\section{A CONSTRUÇÃO DA IDENTIDADE INSTITUCIONAL NA EDUCAÇÃO SUPERIOR}

A evolução histórica do ensino superior brasileiro paira em termos legais norteadores da construção dos modelos institucionais vigentes na contemporaneidade. A reforma universitária de 1968, tal como elenca Brasil (1968), trouxe uma nova perspectiva para a educação superior no Brasil, institucionalizando modelos estruturais especificamente vinculados à constituição de um cenário universitário. Fundam-se, portanto, as estruturas tradicionais encontradas na contemporaneidade, as quais sofreram uma influência dos modelos acadêmicos até então encontrados no segmento, o público e o privado.

Os nortes desta construção buscavam, entre outros aspectos, consolidar um arcabouço no cerne da indissociabilidade entre ensino, pesquisa e extensão, designando atividades essenciais à consolidação da educação superior brasileira e os devidos axiomas vinculados a atuação de instituições públicas e privadas. Seguindo esta linha de pensamento, Oliven (2002), reitera a contribuição mútua destes segmentos, promulgando uma filosofia austera e significativa para cada tipo de ambiência. Assim, portanto, torna-se factível a participação eminente das entidades governamentais nesta construção, seja por investimentos e subsídios às instituições privadas, ou pela concepção e institucionalização das universidades públicas.

A Constituição Federal, promulgada em 1988, consolidou a atividade educacional, sobretudo ao institucionalizar as funções da universidade e as linhas gerais para a educação no País. Neste documento, no cerne do ensino superior, destacam-se as contribuições relevantes do Art. 207, consolidando as ações da universidade, e o Art. 209, corroborando com as responsabilidades da educação superior privada.

Em epítome, às instituições públicas foram delegadas as funções epistemológicas do ensino, sobretudo a partir das atividades vinculadas a pesquisa e a extensão, consolidando métricas, indicadores e atividades vinculadas à construção, sistematização, institucionalização e transferência de conhecimento, fato designado por Bollinger e Smith (2001) como função intrínseca da educação superior. Já as instituições privadas, tendo o mesmo ensejo como função, passam a atuar especificamente na ambiência do ensino, destacando suas atividades aderentes ao mercado e as realidades do entorno no qual estas se inserem (BERTONLIN, 2004).

Com a promulgação da Lei de Diretrizes e Bases da Educação Nacional, LDB 9394/96 - passa-se a refletir sobre a questão da democratização do ensino, 
especificamente no segmento superior, consolidando a ambiência dos modelos públicos e privados, salientando as responsabilidades institucionais e consolidando as premissas destacadas por Brasil (1968) e Brasil (1988). Desse modo, as instituições públicas passam a se consolidar como referência às demais e sua institucionalização passa a ser de competência dos governos federal, estadual e municipal. Já as instituições do segmento privado, constituir-se-iam com base nos pressupostos legais, evidenciados pela Lei, dentro das seguintes bases:

Art. 20. As instituições privadas de ensino se enquadrarão nas seguintes categorias:

I -particulares em sentido estrito, assim entendidas as que são instituídas e mantidas por uma ou mais pessoas físicas ou jurídicas de direito privado que não apresentem as características dos incisos abaixo;

II - comunitárias, assim entendidas as que são instituídas por grupos de pessoas físicas ou por uma ou mais pessoas jurídicas, inclusive cooperativa de professores e alunos que incluam na sua entidade mantenedora representantes da comunidade;

III - confessionais, assim entendidas as que são instituídas por grupos de pessoas físicas ou por uma ou mais pessoas jurídicas que atendem à orientação confessional e ideologia específicas e ao disposto no inciso anterior;

IV - filantrópicas, na forma da lei.

Por esta orientação, Fávero (2006), destaca o início de uma reflexão que marca o liberalismo da educação superior e que se consolidou com a publicação, pela Lei 10.721/01, do Plano Nacional da Educação, o qual designou metas de expansão deste segmento e que orientaram as atividades na educação superior e colimam a construção de uma identidade institucional aplicada a cada modelo. Entre outros aspectos, Silva (2008) destaca que esta construção deveria se esmerar, sobretudo, na definição do papel da instituição em sua conjuntura, da construção e do valor de sua marca. Já Frauches e Fagundes (2007) destacam que esta estrutura esta alicerçada sobretudo na qualidade, corroborando o exposto por Brasil (2004).

Com o advento da globalização, especialmente em função da eminente complexidade da tecnologia da informação, Barreyro (2008) destaca que a definição do papel da universidade, seja ela publica ou privada, deve estar alicerçada nos desígnios que busquem compreender a realidade social, visando o desenvolvimento sustentável e a qualificação dos recursos humanos, físicos e sociais que estão ao seu alcance. Neste cabedal, a universidade torna-se uma "organização avançada da sociedade em termos de conhecimen- 
to, de ciência e tecnologia. Em conseqüência, precisa abrir-se à sociedade, e a serviço desta construir melhor qualidade de vida para as populações" (FRANCO, 2004, p. 25).

A construção da marca, em uma abordagem reflexiva, e sua designação de valor, torna-se ponto focal para que as instituições firmem-se no conceito da sociedade e construam uma interação significativa com sua comunidade. É por isso que Franco (2004), Garcia (2006) e Fávero (2006), salientam que esta estruturação deve estar aderente às suas funções, tendo por evidencia a consolidação de suas ações extensionistas neste contexto, as quais ofertam à comunidade suas benfeitorias. Contudo, a estrutura física da instituição passa a ser peculiar neste aspecto, determinando uma percepção acurada e significativa de valor que, de modo inerente, se vincula a qualidade.

A qualidade, por sua vez instituída pelos instrumentos reguladores da educação superior, faz menção da qualificação do ensino e da estruturação semântica da instituição em sua comunidade. Destarte, a contribuição do PAIUB, elencada por Souza (2007) e Sguissardi (2008), é considerada substantiva, ao passo da identificação de métricas, indicadores e metodologias consolidadas pelo SINAES e que advém de uma percepção significativa de todo o arcabouço institucional. Ademais, portanto, confirma-se o exposto por Bonitatibus (1989) e Melo at al (2006), destacando a contribuição do modelo de educação comparada no sentido da consolidação institucional, onde a avaliação tem função substantiva, equacionadora e epistemológica.

\section{O RETROSPECTO DA AVALIAÇÃO INSTITUCIONAL NO BRASIL}

No contexto brasileiro, especificamente no âmbito da educação superior, as reflexões sobre a Avaliação Institucional estão cercadas de embates contundentes no sentido de consolidar uma epistemologia designada ao termo, sobretudo no sentido de promover o respeito à diversidade de instituições encontradas no Brasil. Nesse contexto, Schwartzman (1989) destaca que o posicionamento do conceito ganha força a partir da reforma universitária de 1968, onde a educação superior no Brasil consolida seu modelo semântico, tal como elencado na contemporaneidade. Assim sendo, inicialmente ensejava-se um modelo imperativo, democrático e sustentável, no sentido de consolidar uma identidade institucional de acordo com as premissas propostas a educação superior no País.

A busca por esta construção se amparava em uma reflexão democrática, no sentido de consolidar uma investigação interdependente, a qual permitiria 
posicionar as atividades de ensino, pesquisa e extensão no contexto da sustentabilidade, promovendo a construção do conhecimento na gênese da instituição. É nesta conjectura que Dias Sobrinho (2008) destaca que a Avaliação Institucional na educação superior brasileira busca, desde então, se tornar um instrumento de transformação social e uma metodologia sistemática que rompe com ideologias institucionais e de curso. Contudo, os modelos até então propostos, pairam na estrutura paradigmática e política da educação superior, onde o mercantilismo educacional se vale sobre a filosofia central da instituição, prevalecendo is rankings ao invés de uma percepção acurada da construção institucional (SCHLICKMANN; MELO; ALPERSTEDT, 2008).

Em seus aspectos teórico-metodológicos, a avaliação é vista com resistência pelos diversos segmentos da comunidade acadêmica das instituições de educação superior brasileiras. Por isso, Ristoff (1999) destaca que os diversos modelos já designados as instituições brasileiras pairavam na falta de aderência e na visão coberta por ideologias políticas e em valores deturpados, confirmando as exposições de Meyer (1993), onde a avaliação, sobretudo nas IES, deveria se constituir em um modelo gerencial, mas passa a ser um instrumento burocrático designado a gerar conflitos.

A retórica da avaliação institucional no Brasil, de acordo com Dias Sobrinho (2005), sempre buscou a consolidação de uma estrutura democrática, ensejando a indissociabilidade entre ensino, pesquisa e extensão preconizada pelos instrumentos legais da educação superior. Contudo, tal como elenca Schlickmann, Melo e Alperstedt (2008), os pressupostos da mão invisível sempre ganharam conotação imperativa no segmento universitário brasileiro, influenciando todos os modelos estruturados até o momento. Desse modo, as reflexões institucionais tendem-se para o mercado, esquecendo da principal função da instituição de educação superior, elencada por Chauí (2003) como sendo a formação e não a simples transmissão de conhecimentos.

Obstante a estes aspectos, os modelos preconizados pelas políticas nacionais ensejaram a consolidação da participação da comunidade acadêmica no contexto da estruturação de uma identidade institucional. Já em 1976, assim como elencado por Schlickmann, Melo e Alperstedt (2008), surge o primeiro modelo estruturado com base nas contribuições da Coordenação de Aperfeiçoamento do Pessoal de Nível Superior - CAPES - que se destacava por seu caráter pragmático e objetivo, buscando um retrato predominantemente quantitativo do posicionamento da educação superior. Este modelo, assim como todos os demais, possuía um caráter punitivo, com influencias das políticas de governo vigentes na época. 
A partir da constituição do Ministério da Educação, em 1983, Bertolin (2004) destaca o surgimento do Programa de Avaliação da Reforma Universitária, o qual possuía um viés ideológico e político amparado em conceitos burocráticos e, por tal fato, não se consolidou em sua estrutura. Desse modo, SINAES (2003) evidencia o fato de que o PARU não obteve a adesão significativa para sua continuidade e acabou por sucumbir aos desígnios políticos que culminaram em seu encerramento. Tal como os modelos anteriores, Zainko (1998) e SINAES (2003) destacam o surgimento de dois novos modelos que esbarram na resistência da comunidade acadêmica, especificamente em função das inferências causadas na autonomia universitária.

Já em 1988, com o advento da Constituição Federal, surge uma nova proposta para a educação brasileira em todos os seus níveis, culminando com uma série de reflexões que constituíram um novo modelo avaliativo para o ensino superior brasileiro. O Programa de Avaliação Institucional das Universidades Brasileiras - PAIUB - estruturou uma proposta abrangente e participativa, prezando por inferências democráticas, buscando ser livre de ideologias e instituindo princípios a serem cumpridos em seu desenvolvimento (RISTOFF, 1999).

Em sua concepção, o PAIUB passa a sistematizar uma avaliação com base na participação da comunidade acadêmica a partir de uma contribuição interdependente da Avaliação das Condições de Ensino, desenvolvidas por comissões de especialistas e o Exame Nacional de Cursos - ENC -, conhecido como "Provão". Ristoff(1999) salienta a relevância deste procedimento no fato de consolidar princípios institucionais, os quais mais tarde dariam sustentação ao SINAES, e que seriam um "meio" para a integração entre a investigação avaliativa e os procedimentos de regulação e supervisão, considerando, no escopo deste processo a avaliação interna das instituições.

Em epítome, em um momento de liberalismo ensejado pela Lei de Diretrizes e Bases da Educação Nacional - Lei 9394/96, este modelo proporcionou diferenciais competitivos na educação superior brasileira, mas caiu em descrédito em detrimento do ranqueamento promovido pelos idealizadores da educação mercantilista. Dessa forma, com base na expansão que acometeu o ensino superior, especificamente pelas vias do segmento privado, em 2003 surgia uma nova reflexão que buscasse estruturar o modelo de avaliação do ensino superior brasileiro, culminando no modelo atual designado as instituições de educação superior, a saber, denominado de Sistema Nacional de Avaliação da Educação Superior no Brasil - SINAES (2004). 


\subsection{A Retórica do SINAES}

O ensino superior, em uma abordagem epistemológica, parte do pressuposto que direciona a formação de agentes capacitados a refletir de modo sistêmico na orientação construtivista de uma nova sociedade. Sob este contexto, Mello (2002) destaca o aspecto colaborativo da Universidade no sentido de promover a qualificação do entorno no qual ela está inserida. Contudo, para que tal fato se consolide, há de se observar os dispostos constitucionais inerentes ao exercício do ensino superior, especificamente na observância de seus aspectos de qualidade.

A Lei de Diretrizes e Bases da Educação Nacional - LDB - regulamenta o disposto no texto constitucional, orientando os pressupostos elencados no sentido da promoção do ensino superior com qualidade. No lume de seu artigo 209 expõe-se os direcionamentos vinculados a oferta do ensino superior sob a égide das questões vinculadas a qualidade. Sob estes aspectos, a avaliação da qualidade no ensino superior passa a regular e direcionar a autorização e o credenciamento de novas instituições a partir de preposições elencadas pelos órgãos reguladores.

Com as bases centradas nestes aspectos, a Lei 10.861/04 institui a proposta de avaliação do ensino superior brasileiro, amparada em um modelo norteador da oferta do ensino superior a partir de especificidades estruturais, técnicas, conceituais e metodológicas das instituições publicas e privadas. Por isso, institui-se o Sistema Nacional da Avaliação do Ensino Superior - SINAES - com vias a regulamentar as atividades das instituições brasileiras a partir de dimensões e grupos de indicadores aplicados aos modelos complexos do cenário nacional.

Em seu escopo, tal como elenca SINAES (2009), trata-se de uma retórica reflexiva, o qual busca, entre outros aspectos, sustentar um modelo que promova a integração e a proatividade institucional sob a orientação de pressupostos relevantes à construção de um sistema avaliativo. Este, por sua vez, ensejava a estruturação dos compromissos sociais das instituições, por meio da consolidação de seus valores sustentados na busca constante da construção de sua identidade por meio de uma reflexão democrática e autônoma.

A partir desta orientação, SINAES (2009) confirma as inferências de Brasil (2004) e destacam a necessidade de uma reflexão participativa e que leve em consideração a articulação coerente entre os agentes vinculados à operação institucional. Neste caso, o corpo social da instituição e as instâncias governamentais passam a refletir sobre as inferências teórico-metodológicas do modelo proposto, articulando práticas sistêmicas e coerentes a partir de uma concepção voltada ao ensino superior. Destarte, resguardando-se as devidas proporções, 
o modelo proposto à avaliação passa a ser considerado uma construção da coletividade acadêmica, orientando a tomada de decisão nas esferas políticas, andragógicas, gerenciais e sociais, consolidando os aspectos de qualidade e auto-regulação no âmbito das instituições.

Este arcabouço metodológico passa a construir uma epistemologia direcionada aos aspectos de qualidade na orientação e oferta do ensino superior, especificamente por meio de um processo participativo, sistêmico e articulado, o qual envolve o poder público. Apesar das diversas controvérsias encontradas na referida construção, o sistema funda-se no composto de ações institucionais, governamentais e sociais, dentro de um cenário formal e regulador que direciona papéis e as especificidades profissionais, políticas, formativas e administrativas das diversas categorias de instituições no cerne nacional. Sob este aspecto, a evidência da avaliação institucional passa a ser "irrecusável não só por razões técnico-administrativas e de adequação às exigências legais, mas, sobretudo, pelo imperativo ético da construção e consolidação das instituições e do sistema de educação superior com alto valor científico e social" (SINAES, 2009, p. 92).

A partir desta reflexão, a complexidade das organizações acadêmicas no âmbito do ensino superior consolida as premissas que requerem a utilização de diversos instrumentos, especificamente no sentido de estruturar as metodologias aplicadas ao processo. Entretanto, SINAES (2009) destaca as criticas subjacentes ao modelo, tendo em vista as práticas determinadas a partir de uma visão míope e fragmentada a qual distorce a realidade encontrada no âmbito das diversas instituições brasileiras.

Por meio desta retórica, deve-se considerar o lume proposto, no qual há a reflexão sob as diversas dimensões operantes no sentido de consolidar a qualidade institucional. Entre diversos termos, consideram-se os aspectos vinculados as diferenças de instituições, indivíduos, parâmetros de aprendizagem, ensino, pesquisa, gestão, intervenção social. No contexto descrito, portanto, destacam-se as considerações que elucidam a avaliação a partir de pressupostos conceituais, epistemológicos e práticos, os quais estão aderentes a diversos instrumentos, metodologias e métodos.

Nas bases conceituais de Souza (2007), o sistema de avaliação do ensino superior brasileiro proposto a partir da ótica do SINAES deve promover a consolidação gerencial e epistêmica no sentido de fortalecer o compromisso social, ético, metodológico e conceitual do ensino superior. Desse modo, comprovam-se as evidencias de SINAES (2009), já que este modelo enseja uma avaliação institucional integrada no contexto das dimensões acadêmicas 
e de aprendizagem e da regulação. A primeira visa a construção dos méritos do ensino, especificamente no sentido da emancipação científica, enquanto a segunda fundamenta seus termos no sentido da supervisão, fiscalização e demais aspectos que sustentam a atividade educacional no ensino superior, a saber, os processos de credenciamento e descredenciamento de instituições, autorização, reconhecimento e renovação de reconhecimento dos cursos.

É relevante considerar, com base nas orientações descritas, que um sistema de avaliação, tal como enseja ser o SINAES, deve buscar em sua maiêutica a proposta de integração interinstitucional, ensejando a troca de experiências e a discussão hermenêutica e reflexiva com o objetivo de construir parâmetros norteadores, e não restritivos. Assim como evidencia Esteves (2007), o modelo avaliativo promoveria uma contribuição efusiva no sentido de promover a inteligência competitiva no cerne da instituição, especificamente por meio de indicadores aplicados ao modelo institucional proposto.

Como citado por Brasil (2004) e SINAES (2009) a construção do epistemio do ensino superior no Brasil evidencia a educação como um aspecto social e não mercadológico, destacando a contribuição da complexidade de diversas instituições no sentido de interiorizar o ensino superior brasileiro a partir de uma construção que leve em consideração o compromisso social e formativo sob a égide de premissas e criteriosamente delineadas.

\subsection{Os princípios norteadores do Sistema}

Os aspectos avaliativos devem obedecer às estruturas regulatórias e de controle tal como evidenciado por Brasil (2008). Os processos se estabelecem de maneira a consolidar métodos democráticos e políticas estruturantes que avalizem os termos normativos e de controle, os quais orientem a fiscalização, a supervisão e os métodos de correção de rumos e estruturação institucional. A avaliação, neste contexto, transcende o marco regulatório em sua epistemologia burocrática, ao passo da promoção de um estudo sistemático com o objetivo de refletir sobre as melhores condições e práticas de desenvolvimento institucional.

A partir desta concepção, a avaliação promove aspectos estruturantes e que orientam a democratização do ensino, especificamente nos termos do Plano Nacional da Educação para o decano de 2001 a 2011, com vias a consolidar a atividade acadêmica e a inserção da população no ensino superior amparado pela qualidade. Assim, a concepção prática, burocrática e legalista deste processo é fundamental para solidificar a lógica de um sistema regulatório que não se esgote em si mesmo, mas promova uma articulação construtivista e formativa no âmbito do ensino superior. 
Ao incitar esta reflexão, SINAES (2009) trata da avaliação no âmbito formativo como uma proposta que visa questionar os diversos signos e a semântica do conhecimento produzido em relação ao desenvolvimento sustentável da comunidade acadêmica. Visa-se, a partir desta percepção, a reflexão significativa sob perspectiva dos métodos de julgamento e os pressupostos estruturantes da função docente, a qual direciona a percepção cognitiva do acadêmico na formulação de sua proposta científica e na dinâmica institucional. Desse modo, a avaliação passa a investigar e questionar a compreensão dos aspectos práticos, filosóficos, teóricos e metodológicos da construção do conhecimento no cerne do ensino superior, instituindo procedimentos de controle a partir de objetivos traçados, evidenciando o sentido formativo. Assim, a avaliação nas bases do SINAES (2009), traduz a construção social e a compreensão de conhecimentos e julgamentos de valor sob a partir da compreensão da atividade institucional eficaz e consciente de seus valores fundamentados na qualidade.

Sob este aspecto, portanto, a investigação da qualidade institucional deve levar em conta a conscientização dos agentes institucional e a implementação de uma cultura que vislumbre a compreensão do epistemio do ensino superior plenamente orientado pelos valores democráticos e participativos, numa retórica solidaria, interdisciplinar e interinstitucional.

Em uma abordagem operacional, considerando as especificidades do sistema educacional brasileiro, SINAES (2009) destaca que a avaliação deve estar consubstanciada no respeito à identidade e à diversidade de instituições. Franco (2004) destaca que os diversos modelos institucionais devem ser considerados em suas especificidades operacionais, sistêmicas e semânticas, ao passo da diversidade encontrada no âmbito nacional e que preconiza desafios evidentes à compreensão desta complexidade.

Esta diversificação está alicerçada no arcabouço estruturante da democratização do ensino, tal como evidenciado no PNE em vigência, fundamentando diferentes concepções e desafios. Assim sendo, constroem-se modelos empreendedores a partir da contribuição da complexidade tecnológica, onde as especificidades regionais elencam necessidades a serem absorvidas por estes modelos. Outrossim, a avaliação deve partir de um pressuposto de pluralismo de idéias, construindo uma política cooperativista.

No cenário que se constrói, percebe-se que cada instituição tem sua história e consolida coerentemente suas atividades direcionando os aspectos avaliativos a um processo diversificado de construção da identidade das instituições. 


\begin{abstract}
A avaliação deve servir de instrumento para aumentar a consciência sobre a identidade e, portanto, as prioridades e potencialidades de cada instituição. A identidade institucional não é um já-dado; é uma construção que tem a ver com a história, as condições de produção, os valores e objetivos da comunidade, as demandas concretas, as relações interpessoais. Portanto, a avaliação deve estabelecer um elo de ligação entre o específico e o institucional e o sistema de Educação Superior. O respeito à identidade não significa isolamento institucional e sim uma condição para a solidariedade interinstitucional (SINAES, 2009, p. 98).
\end{abstract}

No cerne destes princípios, destaca-se o fato do respeito a globalidade, especificamente como uma resultante da compreensão da diversidade de modelos institucionais. É por isso que SINAES (2009) se ampara na assertiva de que a avaliação institucional deve estar consubstanciada em diversos instrumentos de regulação que se articulem a uma sistemática integrada a uma política de estado no âmbito do ensino superior. Destarte, o SINAES enseja a implementação de roteiros e propostas globais que visem a regulação e a estruturação de discussões e reflexões na forma de estudos e juízos de valor numa perspectiva multidimensional vinculada aos termos quantitativos e qualitativos da oferta do ensino superior.

Dentro desta perspectiva, a avaliação institucional reduz as duvidas e ambigüidades e consolidam as práticas hermenêuticas no sentido de promover o ensino superior de qualidade e que permitam compreender os limites metodológicos, complexos e multidimensionais da avaliação. Assim como evidencia Brasil (2006), Frauches e Fagundes (2007) e Silva (2008), a avaliação institucional em um substrato polissêmico deve, portanto, articular diversos instrumentos, dimensões e sentidos a partir das diversas estruturas do ensino superior no Brasil.

A partir daí é possível compreender a avaliação institucional como uma evidencia política e de poder, perpassando os aspectos técnicos e metodológicos em função da promoção de sua legitimidade. Busca-se evidencias concretas de um desenvolvimento sustentável da avaliação sob a orientação de seus sentidos políticos e éticos e que envolvem as concessões das organizações do ensino superior, da sociedade e do estado.

Por este ponto de vista, SINAES (2009 e 2004) traduzem os esforços estruturantes da avaliação a partir de uma concepção democrática de educação e da avaliação que confere aos processos avaliativos sob as estruturas éticas e políticas, técnicas e conceituais, onde "os processos de avaliação movem-se dentro de um marco ético, em que devem estar garantidos alguns critérios: liberdade no debate argumentativo, negociação, solidariedade (cooperação), equidade 
(tratamento justo e adequado), compromisso social com o conhecimento, com os valores socialmente distinguidos e com a responsabilidade pública.

Por fim, os aspectos vinculados as premissas norteadoras do sistema ensejam a continuidade, destacada por SINAES (2009) e Brasil (2006) como fatos inerentes a um processo continuo e permanente, e não episódicos, pontuais e fragmentados. Deve-se buscar evitar a avaliação como sendo um processo rotinizado, burocrático e legalista, suprimindo seu potencial de reflexão e transformação permanente. Assim sendo, deve-se estruturar um pressuposto avaliativo que denote práticas internalizadas como cultura de melhoramento e emancipação, assumindo suas responsabilidades na construção do ensino em consonância com os interesses, valores da sociedade e instituições.

Tendo em vista essencialmente melhorar o cumprimento da responsabilidade social e científica das instituições em particular e da Educação Superior em seu conjunto, o SINAES propõe-se a incorporar aos processos avaliativos todos os agentes, todas as dimensões e instancias das IES, respeitados os papeis específicos dos participantes, a identidade e a missão de cada uma delas. (SINAES, 2009, p. 102).

A partir desta reflexão, consequentemente, a avaliação institucional deve ensejar o pressuposto da continuidade, respeito à identidade institucional e sistematização, constituindo-se em instrumento de validação e ampliação dos objetivos propostos e de procedimentos de instrumentação e investigação que remetem a construção de um conceito amparado na qualidade e orientação da oferta do ensino superior no Brasil.

\section{PROCEDIMENTOS METODOLÓGICOS}

O aporte metodológico no sentido de promover a compreensão da problemática elencada ao tema apresenta teve suas bases sustentadas em métodos específicos e delineados a partir da instrumentação científica. Com base nas contribuições de Souza, Fialho e Otani (2007), a pesquisa, designada a elucidar os questionamentos da pesquisa, faz jus de procedimentos apresentados a partir da classificação, técnica empregada, natureza, objetivos, abordagem do problema, fontes de informação e procedimentos técnicos. Os participantes, neste contexto, foram dez profissionais que participaram de procedimentos de avaliação in loco em instituições de educação superior nas cinco regiões do Brasil. 
Nos aspectos da classificação, a pesquisa qualifica-se como sendo uma pesquisa acadêmica, corroborada por Sousa, Fialho e Otani, como sendo propulsora de aspectos que determinam a construção, a produção e a sistematização do conhecimento no âmbito da academia. Já quanto a técnica empregada, destaca-se a contribuição da documentação indireta, tendo em vista a utilização de fontes primárias e secundárias, por meio de levantamentos bibliográficos, direcionados a consolidação da fundamentação teórica e o aporte do resultado das entrevistas realizadas com profissionais que realizam procedimentos avaliativos (ZAPELINI; ZAPELINI, 2007).

Quanto a natureza, a pesquisa possui o caráter aplicado, já que conforme Zapelini e Zapelini (p. 95) “ identifica a situação-problema e busca, dentre as possíveis soluções, aquela que possa ser mais adequada para o contexto específico". Em seus aspectos epistemológicos, a pesquisa não tem a pretensão de criar conhecimentos novos, mas sistematizar o existente e adaptá-lo à situação problema. Já quanto aos objetivos, a pesquisa tem seu caráter descritivo-explicativo, pois confirma-se o exposto por Hair Jr. et al (2005) e Vergara (2005), visto que a investigação tem, em seus objetivos, a intenção de mensurar características descritas, construindo hipóteses que guiam o processo e analisar um fenômeno na busca de esclarecimento, tornando-o compreensível e justificável.

No sentido da abordagem do problema, a pesquisa classifica-se como sendo qualitativa, onde colima-se o exposto por Chizzotti (2006), visto que a investigação busca extrair significados visíveis e latentes, e confirma-se a reflexão de Malhorta (2001), já que a pesquisa busca promover a melhor compreensão do contexto do problema.

Como aporte, com vias a consolidar a investigação, utilizam-se, como fontes de informação, as bases da pesquisa bibliográfica, que conforme Dencker (2000) utiliza-se de fontes teóricas para consolidar a fundamentação teórica, e da pesquisa de campo, já que é feita em um âmbito específico, na busca de elementos que permitam explicar determinado fenômeno, neste caso um aspecto inerente a educação superior, utilizando-se, para tal, entrevistas semiestruturadas que, com base nas exposições de May (2004) permite identificar uma visão geral do entrevistado sobre determinado assunto, utilizando-se um roteiro que permita, entre outros aspectos, obter a contribuição do entrevistado.

Por fim, quanto aos procedimentos técnicos, a pesquisa classifica-se como sendo uma pesquisa participante, já que com base em Souza, Fialho e Otani (2007), permite a interação entre o pesquisador, os pesquisados e componentes das situações ou fenômenos investigados, tendo, também, as contribuições 
da pesquisa-ação, ensejando a participação ativa do pesquisador, buscando elucidar aspectos inerentes à problemática elencada.

\section{REFLEXÕES SOBRE A AVALIAÇÃO IN LOCO}

A partir de uma abordagem sistêmica, a Avaliação Institucional, tal como concebida por SINAES (2004) trata de uma perspectiva reflexiva, na qual a construção semântica se faz por meio de inferências participativas em um bojo processual que culmina na disposição institucional. Esta, por sua vez, serve de referência para os processos regulatórios dos órgãos reguladores da educação superior brasileira, a qual busca, entre outros aspectos, consolidar um sistema de avaliação condizente com a estrutura organizacional das universidades brasileiras.

Dentro do escopo deste processo, a Avaliação in loco é o procedimento que culmina na consolidação da expertise institucional, tendo em vista a reflexão promovida por seus agentes com base nas atividades desenvolvidas durante o ciclo estipulado. Nunes (2006) destaca que a inferência da comunidade acadêmica traz a luz uma perspectiva inerente à continuidade da instituição, consolidando seus métodos acadêmicos e construtivos. É neste momento que o Plano de Desenvolvimento Institucional - PDI - ganha relevância no processo, servindo, tal como elenca Brasil (2006), como documento-base para o desenvolvimento das reflexões.

Em seus diversos momentos, o processo avaliativo tem diferentes abordagens, sendo que tais se concluem de acordo com a devida finalidade proposta. Em todos os casos, desde o credenciamento, passando pela autorização, reconhecimento, renovação de reconhecimento de cursos e o recredenciamento, este processo constitui-se em um momento de interlocução, onde o envolvimento da comunidade acadêmica ganha escopo e relevância no sentido de verificar a aderência da proposta institucional com os projetos em desenvolvimento e com o suporte físico e estrutural ensejado para tal cumprimento (BRASIL, 2004).

Na conjuntura contemporânea da educação superior brasileira, o processo de Avaliação in loco torna-se relevante no sentido de qualificar as ações gerenciais da instituição. É um momento no qual as reflexões da educação superior, especificamente no âmbito institucional, são confrontadas e colocadas a disposição de profissionais que, tal como salienta Souza (2007), são capacitados para compreenderem a identidade institucional de cada modelo, considerando, entre outros aspectos, os princípios e a diversidade das instituições brasileiras. 
O surgimento do Índice Geral de Cursos - IGC - instituído pela Portaria Normativa $\mathrm{N}^{\circ} 12$ de 5 de setembro de 2008, contudo, promoveu uma intensa discussão sobre a eficácia da Avaliação in loco, já que tal índice prejudicará, substantivamente, a reflexão interna na instituição. Dentro de sua estrutura, as instituições passam a ficar a mercê de dados quantitativos e objetivistas, suprimindo um trabalho significativo de investigação realizado no cerne institucional (LEHFELD et al, 2010).

Esta discussão, contudo, não trouxe efeitos significativos no processo de Avaliação in loco, já que este pôde se posicionar, mesmo em função de aspectos quantitativos e pragmáticos, como um momento no qual a instituição busca, com o auxilio de especialistas, compreender sua cultura e compreender sua função social. Assim como nas evidencias de Andriola e Souza (2010), essa compreensão permite que a instituição se veja livre de ideologias impositivas e consolide-se como um agente de construção de conhecimento, ofertando suas contribuições aos ensejos da sociedade. E neste procedimento sistemático, a discussão com profissionais especialistas viabiliza, entre outros aspectos, a estruturação de uma identidade com base em paradigmas inerentes ao seu posicionamento.

Os aspectos norteadores deste momento buscam, em seus meios, consolidar os princípios designados pelo SINAES, bem como elucidar as potencialidades e fraquezas identificadas, contribuindo para a consecução dos objetivos institucionais e para a consolidação da identidade da instituição. Portanto corrobora-se a contribuição de Fontanive e Klein (2000), já que passam a ser evidenciados efeitos positivos das políticas institucionais ensejadas pela instituição, livrando-se, sobretudo, das ideologias que cercam a educação superior brasileira. Destarte, a Avaliação in loco parte de um pressuposto construtivo e reflexivo, o qual enseja a continuidade do processo de transformação social promovido pelas instituições de educação superior, designando, com base nas reflexões direcionadas por como versa Dias Sobrinho (2008), ações que permitam uma atuação coerente com seus ideais, superando suas expectativas no contexto da complexidade da era do conhecimento.

\subsection{A Avaliação como fator corroborante dos princípios estrutur- antes do SINAES}

Os princípios estruturantes do SINAES promovem uma retórica substantiva no sentido de promover uma compreensão específica sobre a relevância da educação superior brasileira. SINAES (2009) evidencia as premissas norteadoras do sistema, onde destacam-se os seguintes: a educação como direito social e 
dever do estado, os valores sociais da instituição os quais são historicamente determinados, regulação e controle, a educação como prática social com objetivos educativos, o respeito a identidade e a diversificação institucional, a globalidade, a legitimidade e a continuidade. Destarte, dentro do ponto de vista dos avaliadores $a d$ hoc, estes aspectos consolidam o sistema de avaliação no Brasil, evidenciando pontos específicos que qualificam cada termo.

A educação, em todos os seus níveis, tornou-se fator preponderante nas bases constitucionais brasileiras. A Lei de Diretrizes e Bases da Educação Nacional - LDB - traz a luz o fato de que a educação é um dever da família e, entre outros aspectos, sustenta o fato de que a educação superior é um direito social. Assim sendo, com base na sistematização dos dados da pesquisa, este aspecto se consolida dentro dos procedimentos específicos da avaliação, respeitando a liberdade designada a cada avaliador no sentido de buscar a epistemologia da instituição, consolidando sua identidade e salientando a relevância social da instituição em seu entorno. Na avaliação institucional, sobretudo nos procedimentos da avaliação in loco - busca-se identificar os aspectos que confirmam os pressupostos explícitos e que corroboram as práticas institucionais de acesso e permanência no ensino superior e, portanto, urge que este ponto se consolide ao passo das práticas evidenciadas pelas instituições que promovam a inserção e a permanência na educação superior.

Ao passo da busca pelos valores sociais da instituição, torna-se relevante identificar o histórico, o posicionamento estratégico e suas práticas operacionais já que, conforme Machado (2008) é aspeto que consolidam o modelo gerencial da instituição. Neste sentido, em vias de consolidar os valores institucionais como princípio estruturante do SINAES, torna-se importante considerar a cultura institucional e obter conhecimentos específicos ao desempenho acadêmico e administrativo da instituição, evidenciando seus pontos fortes e direcionando trabalhos específicos voltados aos seus pontos fracos.

A regulação e o controle, com base nas exposições de Kleber e Trevisan (2010), ainda trazem diversos aspectos que causam confusão no sentido de avaliação institucional no Brasil. Há uma dificuldade significativa em compreender três termos específicos da investigação qualitativa nas instituições brasileiras, tal como evidenciam as reflexões de Giolo (2008), posicionando, dentro das práticas acadêmicas, os conceitos designados por SINAES (2009), a saber: avaliação, regulação e supervisão.

Em específico, a regulação e o controle passam a ser incisivos no processo de avaliação, considerado por SINAES (2009) como sendo um dos princípios estruturantes do SINAES. A investigação evidencia que, apesar das controvérsias 
identificadas em relação aos termos, o processo avaliativo posiciona a regulação e o controle a partir da identificação do nível de absorção dos termos legais da educação superior pela comunidade acadêmica da instituição. Entre outros aspectos, isso permite promover um debate inerente as funções institucionais da educação superior e posicionar de maneira correta não apenas a regulação e o controle, mas, também, a avaliação e a supervisão.

Assim como destaca SINAES (2009), a regulação e o controle se posicionam como um principio norteador do sistema no momento em que busca-se compreender o nível de compreensão da comunidade acadêmica dos aspectos relacionados aos instrumentos reguladores da educação superior no Brasil, posicionando as reflexões no âmbito de uma discussão construtivista na instituição, tendo como base a apropriação dos instrumentos e dos aspectos regulatórios e legais da educação superior brasileira.

Na sequencia das investigações, identificam-se os aspectos que consolidam o principio de que a educação superior, assim como evidenciada por SINAES (2009), é uma prática social com objetivos educativos, a qual deve consolidar o conceito de educação no contexto institucional. O resultado das investigações heurísticas apontam para o cumprimento deste aspecto no momento onde realiza-se a leitura do PDI, identificando as políticas institucionais designadas na estrutura documental, tal como elenca Brasil (2006). Destarte, as práticas institucionais descritas no documento, e o paralelo realizado com a realidade encontrada na instituição, permitem identificar o nível de absorção do conceito de educação pela comunidade acadêmica, além de permitir a constatação das finalidades institucionais propostas pela sua inserção social.

Sob estes pressupostos, Brasil (2006) destaca que o sistema de educação superior no Brasil é diversificado e instrumentaliza métodos para a consolidação deste ambiente, altamente complexo, e que requer uma investigação constante na busca pela qualidade. Urge, consequentemente, que se enseje um processo avaliativo democrático, onde a principio que confirme o respeito à identidade institucional e a diversidade do sistema, destacado por SINAES (2009) e Brasil (2008), colime-se no âmbito das práticas acadêmicas e administrativas da instituição.

As investigações destacam que o respeito a este aspecto se dá no momento em que a avaliação promova um debate significativo entre as práticas institucionais e estrutura disponibilizada para a oferta da educação, onde as políticas e os recursos institucionais disponibilizados a comunidade acadêmica são fundamentais. Por meio desta reflexão, portanto, há de se considerar o escopo da instituição ofertado a comunidade acadêmica. 
Com base na contribuição da comunidade acadêmica, a globalidade se posiciona como um aspecto fundamental à avaliação no momento em que se identifica a contribuição de todos os agentes da comunidade acadêmica, designada por Brasil (2004) como sendo essencial. A participação de todos os segmentos é fator decisivo na consolidação do processo avaliativo, promovendo, entre outras possibilidades, o fato de consolidar a avaliação como processo construtivista e maiêutico na instituição, posicionando, também, a legitimidade do processo, com a contribuição de todos na construção dos instrumentos, e determinando a continuidade do processo, designada por SINAES (2009), por meio da construção de novos indicadores que promovem a evolução da instituição e do segmento como um todo.

\section{CONCLUSÕES}

A avaliação institucional estrutura-se a partir da busca constante pela consolidação de um sistema autônomo e que evidencie a convergência processual vinculada ao fortalecimento dos compromissos sociais da instituição, sobretudo em seus aspectos direcionado ao aprendizado, respeito à identidade institucional e ao contexto no qual a instituição esta inserida. Nestes termos, confirmam-se os pressupostos evidenciados por Souza (2007), os quais tratam a avaliação institucional sob a orientação do SINAES como sendo um modelo de gestão orientado, amparado no contexto da operacionalização estatal, orientado à construção institucional a partir de um direcionamento inerente a epistemologia da entidade e ao fortalecimento de suas evidencias educativas.

A partir da proposta inicial designada como problemática desta produção, conclui-se que a contribuição da avaliação in loco, sobretudo por meio da participação dos avaliadores ad hoc promove uma significativa relação entre a sociedade e a instituição de educação superior, no sentido de constituir um debate significativo que versa sobre a consolidação do SINAES. Por meio deste processo, há de se constituir métodos e técnicas que evidenciam a estrutura do sistema, sobretudo ao passo de se consolidar um sistema de avaliação dinâmico e coerente com as práticas ensejadas pelos órgãos reguladores da educação superior no Brasil.

De modo geral, o objeto de estudo da avaliação, com base nas orientações do SINAES (2009), determina um estudo sistêmico do conjunto de analises e dimensões, e dos aspectos estruturais vinculados as atividades de ensino, pesquisa e extensão, além daqueles que evidenciam as práticas 
gerenciais da instituição. Com as bases neste pressuposto, a avaliação enseja a convergência de esforços entre os agentes responsáveis por tal construção, destacando os membros da comunidade acadêmica como sendo fundamentais nesta circunstância, sobretudo ao passo da relevante contribuição frente a consecução dos objetivos e na determinação dos procedimentos metodológicos utilizados.

A partir destes critérios delineados, especificamente no âmbito do ensino, Brasil (2006) trata a avaliação como sendo instrumento inerente às funções institucionais e específicas à formação social a partir de uma prática arrolada aos objetivos educativos. Sob estes pressupostos, a avaliação parte de uma reflexão educativa e social, tendo seus objetivos amparados na questão formativa e voltada para a obtenção de resultados que promovem o construtivismo e o delineamento de práticas que ensejem o cumprimento das funções públicas do ensino superior.

O processo de Avaliação in loco, no contexto do SINAES, parte do pressuposto sistêmico, proposto por Brasil (2004) e esmera-se no pretexto construtivo, sobretudo, no âmbito da reflexão, na qual a instituição torna-se responsável, assim como evidencia Silva (2008), pela construção, ou consolidação, de sua identidade institucional. Desse modo, portanto, este processo deve se amparar na convergência dos princípios propostos pelo SINAES e destacados por SINAES (2009) como sendo aspectos estruturantes ao modelo avaliativo proposto para a educação superior brasileira, onde a contribuição ocorre de maneira democrática e parte das atividades dos responsáveis pela avaliação e pela comunidade acadêmica da instituição.

É neste momento onde se identifica se, de fato, a educação é tratada de acordo com as finalidades propostas, tendo seu aspecto social consolidado e sem a proeminência de práticas mercantilistas. Neste momento, é importante citar que o PDI, em sua estrutura designada por Brasil (2006) deve apresentar um escopo de acordo com a identidade institucional, onde as políticas institucionais consolidam a percepção da instituição sobre o conceito de educação.

Com base nestes pressupostos, pode-se concluir que, do ponto de vista dos avaliadores ad hoc, os aspectos que determinam o cumprimento dos princípios estruturantes do SINAES, no contexto das instituições de educação superior no Brasil ensejam uma reflexão constante e continua no sentido de compreender a estrutura semântica da educação no País, determinando, entre outros aspectos, a possibilidade de acompanhar a complexidade dinâmica que determina o posicionamento da educação superior no Brasil. 


\section{REFERÊNCIAS}

ANDRIOLA, Wagner B.; SOUZA, Laura A. Representações sociais dos gestores e dos técnicos das unidades acadêmicas da Universidade Federal do Ceará (UFC) acerca da autoavaliação institucional. Avaliação, Campinas; Sorocaba, SP, v. 15, n. 1, p. 177-194, mar. 2010.

BARREYRO, Gladys. B. Mapa do ensino superior privado. Série documental. Relatos de pesquisa. Brasília: INEP, 2008.

BERTOLIN, Julio. C. A transformação do SINAES: da proposta emancipatória à Lei híbrida. Avaliação, Campinas; Sorocaba, SP, v. 9, n. 4, p. 67-97, dez. 2004.

BITTENCOURT, Hélio Radke; CASARTELLI, Alam de Oliveira; RODRIGUES, Alziro César de Morais. Sobre o índice geral de cursos. Avaliação, Campinas; Sorocaba, SP, v. 14, n. 3, p. 667-682, nov. 2009.

BOLLINGER, Audrey S.; SMITH, Robert.D. Managing organizational knowledge as a strategic asset. Journal of Knowledge Management, Teleos, Reino Unido, v. 5, n. 1, p. 8-19, 2001.

BONITATIBUS, Suely Grant. Educação comparada: conceito, evolução, métodos. São Paulo: EPU, 1989.

BRASIL, Presidência da república. Decreto 5773 de 9 de maio de 2006. Subchefia para assuntos jurídicos. Brasília, 2006.

BRASIL, Presidência da Republica. Decreto 6.425, de 4 de abril de 2008. Casa Civil: Subchefia para assuntos jurídicos, 2008.

BRASIL, Presidência da Republica. Lei 10.861, de 14 de Abril de 2004. Brasília, 2004.

BRASIL. Constituição: República Federativa do Brasil, Brasília: Senado Federal, Centro Gráfico, 1988.

BRASIL. Presidência da Republica. Lei 5.540, de 28 de novembro de 1968. Casa Civil: Subchefia para assuntos jurídicos: 1968.

CHAUI, Marilena. A universidade pública sob nova perspectiva. Revista Brasileira de Educação, Rio de Janeiro, n. 24, p. 5-15, set/dez.2003. 
CHIZZOTTI, Antonio. Pesquisa qualitativa em ciências humanas e sociais. Petrópolis: Vozes, 2006.

DENCKER, Ada de F. M. Métodos e técnicas de pesquisa em turismo. 4. ed. São Paulo: Futura, 2000.

DIAS SOBRINHO, José. Qualidade, avaliação: do SINAES a índices. Avaliação, Campinas; Sorocaba, SP, v. 13, n. 3, p. 817-825, nov. 2008.

DIAS SOBRINHO, José. Avaliação como instrumento da formação cidadã e do desenvolvimento da sociedade democrática: por uma ético-epistemologia da avaliação. In: RISTOFF, Dilvo Ilvo (Org.). Avaliação participativa: perspectivas e debates. Brasília: INEP, 2005.

DIAS SOBRINHO, José. Qualidade, avaliação: do SINAES a índices. Avaliação, Campinas; Sorocaba, SP, v. 13, n. 3, p. 817-825, nov. 2008.

ESTEVES, Paulo Cesar. L. Fatores determinantes de mudanças na estrutura competitiva do sistema de ensino superior de Santa Catarina. Tese. 154f. (Tese de Doutorado). Programa de Pós-Graduação em Engenharia e Gestão do Conhecimento. Universidade Federal de Santa Catarina, 2007.

FAVERO, Maria de Lourdes Albuquerque. A universidade no Brasil: das origens à reforma universitária de 1968. Educar, Curitiba, n. 28, p. 17-36, 2006.

FONTANIVE, Nilma Santos; KLEIN, Rubem. Uma visão sobre o sistema de avaliação da educação básica do Brasil (SAEB). Ensaio: Avaliação e Políticas Públicas em educação, Rio de Janeiro, v. 8, n. 29, p. 29, p. 409-442, out./dez. 2000.

FRANCO, Edson. Em busca da identidade no ensino superior particular: uma experiência particular. Brasília: ABMES, 2004.

FRAUCHES, Celso. Costa; FAGUNDES, Gustavo. Monteiro. LDB anotada e comentada e reflexões sobre a educação superior. 2 ed. Brasília: 2007.

GARCIA, Mauricio. Gestão profissional em instituições privadas de educação superior - Um Guia de sobrevivência para mantenedores, acionistas, reitores, pró-reitores, diretores, coordenadores, gerentes e outros gestores institucionais. 1 ed. São Paulo: Hoper, 2006. 
GIOLO, Jaime. "SINAES" intermitentes. Avaliação, Campinas; Sorocaba, SP, v. 13, n. 3, p. 851-856, nov. 2008.

HAIR JR., Joseph et al. Fundamentos de métodos de pesquisa em administração. Porto Alegre: Bookman, 2005.

KLEBER Klaus; TREVISAN, Leonardo (Org.). Produzindo capital humano. O papel do ensino superior privado como agente econômico e social. São Paulo, Cultura: 2010.

LEHFELD, Neide Aparecida de Souza; GABARRA, Manoel Henrique Cintra; COSTA, Caetano; SOUSA, Yara Teresinha Correa Silva. Reflexões sobre o processo de autoavaliação institucional: o olhar de uma comissão própria de avaliação. Avaliação, Campinas; Sorocaba, SP, v. 15, n. 1, p. 177 194, mar. 2010.

MACHADO, Luis. Eduardo. Gestão Estratégica para instituições de educação superior privadas. São Paulo: FGV Editora 2008.

MALHOTRA, Naresh. K. Marketing research: upper saddle river. 3. ed., Prentice Hall, 2001.

MAY, Tim. Pesquisa social: questões, métodos e processos. 3. ed. Porto Alegre: Artmed, 2004.

MELO, Pedro Antonio; RAMA, Claudio; MELO, Michelle Bianchini de; LUZ, Rodolfo Joaquim Pinto. A formação docente no Brasil, na América Latina e no Caribe. Florianópolis: Paper print, 2006.

MELO, Pedro. A cooperação universidade/empresa nas universidades públicas brasileiras, 2002. 331f. Tese (Doutorado). Programa de PósGraduação em Engenharia de Produção. Universidade Federal de Santa Catarina, 2002.

MEYER, Victor. A busca da qualidade nas instituições universitárias. Enfoque, Rio de Janeiro, v. 4, n. 10, set. 1993.

NOGUEIRA, Janna Flávia Fernandes. Reforma da educação superior no governo Lula: debate sobre a democratização do acesso. 2008. $197 \mathrm{f}$. Dissertação (Dissertação de mestrado). Programa de Pós-Graduação em Educação. Universidade de Brasília: 2008. 
NUNES, Lina Cardoso. As dimensões da auto-avaliação institucional: tecendo redes de redes. Ensaio, Rio de Janeiro, v. 14, n. 52, p. 339-348, jul./ set. 2006.

OLIVEN, Ruben. George. A antropologia de grupos urbanos. 5. ed. Petrópolis: Vozes, 2002.

RISTOFF, Dilvo Ilvo. Universidade em foco: reflexões sobre a educação superior. Florianópolis: Insular, 1999.

SCHLICKMANN, Rafael; MELO, Pedro Antonio; ALPERSTED, Graziela Dias. Enfoques da teoria institucional nos modelos de avaliação institucional brasileiros. Avaliação, Campinas; Sorocaba, SP, v. 13, n. 1, p. 153-168, mar. 2008.

SCHWARTZMAN, Simon. Funções e metodologias da avaliação da educação superior. Documento do núcleo de trabalho do Núcleo de pesquisas sobre o Ensino Superior. São Paulo: USP, 1989.

SGUISSARDI, Valdemar. Regulação estatal versus cultura de avaliação institucional? Avaliação, Campinas; Sorocaba, SP, v. 13, n. 3, p. 857-862, nov. 2008.

SILVA, Renato. Balanced Scorecard - BSC - Gestão do Ensino Superior - Gestão profissionalizada e qualidade de ensino para instituições de ensino superior privado. Curitiba: Juruá, 2008.

SINAES. Sistema Nacional de Avaliação da Educação Superior: bases para uma nova proposta de avaliação da educação superior. Brasília: INEP, 2003.

SINAES. Sistema Nacional de Avaliação da Educação Superior: da concepção à regulamentação. 2. ed. Brasília: INEP, 2004.

SINAES. Sistema nacional de avaliação da educação superior: da concepção à regulamentação. 5. ed. revisada e ampliada. Brasília: INEP, 2009.

SOUZA, Antonio C.; FIALHO, Francisco A. P.; OTANI, Nilo. TCC métodos e ténicas. Florianópolis: Visualbooks, 2007. 
SOUZA, José Carlos Victorino. Gestão universitária em instituições particulares: os documentos institucionais como indicadores do modelo de gestão. Tese (Doutorado). 208f. Programa de Pós-Graduação em Educação e currículo. Pontifícia Universidade Católica de São Paulo, 2007.

VERGARA, Silvia.C. Métodos de pesquisa em administração. São Paulo: Atlas, 2005.

ZAINKO, Maria Amélia Sabbag. Planejamento, universidade e modernidade. Curitiba: All-Graf, 1998.

ZAPELINI, Marcello. B; ZAPELINI, Silvia.M.K.C. Metodologia científica e da pesquisa para o curso de Administração. Florianópolis: Faculdade Energia de Administração e Negócios, 2007. Apostila do curso de Administração. 